\title{
Panoramic and tomographic implant studies: Role in the diagnosis of sinus disorders
}

\author{
José-María Martínez-González ${ }^{1}$, Cristina Barona-Dorado ${ }^{2}$, Oscar Arias-Irimia ${ }^{3}$, Natalia Martínez-Rodrí- \\ guez $^{3}$, Manuel Fernández-Domínguez ${ }^{4}$
}

${ }^{1}$ Full Professor of Maxillofacial Surgery at Complutense University of Madrid. Head of the Department of Oral Facial and Implant Surgery at Madrid Hospital

${ }^{2}$ Assistant Director of the Masters program in Oral Facial and Implant Surgery. Madrid Hospital

${ }^{3}$ Oral Surgeon. Madrid Hospital

${ }^{4}$ Head of the Department of Maxillofacial Surgery. Monteprincipe University Hospital

Correspondence:

Universidad Complutense de Madrid

Facultad de Odontología

Pza. Ramón y Cajal s/ $n$

28040 Madrid, Spain

jmargo@odon.ucm.es

Received: 02/06/2009

Accepted: 28/11/2009

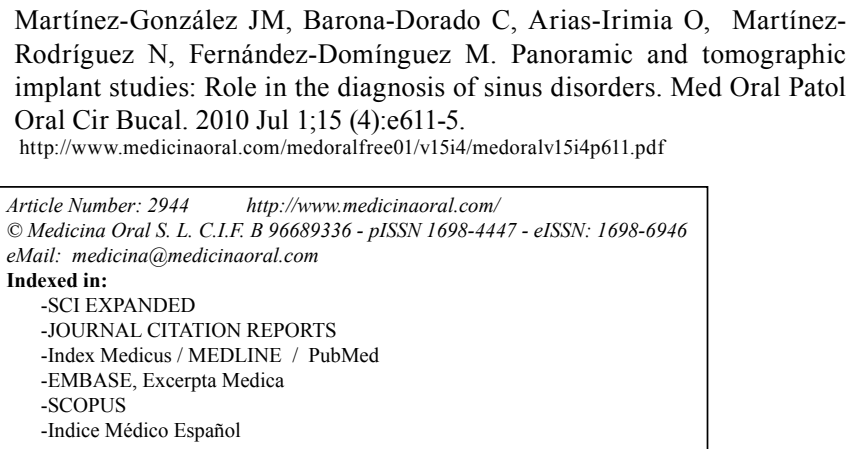

\begin{abstract}
Objective: To study the presence of sinus disorders and their diagnosis based on clinical and radiographic findings, correlating their presence with tomography tests and panoramic radiography.

Study design: We conducted a retrospective study on 152 patients who were seeking implant treatment, thereby allowing us to evaluate 42 patients who had abnormal sinuses. The patients underwent an evaluation of their medical history as well a clinical examination, panoramic radiography and tomographic study.

Results: The average age of the patient was 59.8 years old, and $54.76 \%$ of the group were males and $45.23 \%$ were females. Prior respiratory disorders were present in $52.38 \%$ of the patients, and $57.3 \%$ of the group presented dental disorders. In assessing the type of wound, we observed that $73.21 \%$ were mucosal hyperplasia and $26.78 \%$ were mucous cysts. Of the 56 sinuses affected, only $28.57 \%$ were diagnosed using panoramic radiography.

Conclusions: Panoramic radiography has limitations in the diagnosis of sinus disorders; computerized tomography (CT) remains the most effective diagnostic test.
\end{abstract}

Key words: Maxillary sinus, mucosal hyperplasia, mucous cyst, panoramic radiography, computerized tomography. 


\section{Introduction}

The pathology of hyperplastic sinus mucosa or cystic mucosa has a high incidence in all oral cystic lesions, which some authors estimate to occur in $19.5 \%$ of the cases (1). In most cases, the finding is discovered by chance through routine radiographic examinations. Symptomatic cases may occur when the sinus is completely full, the most common clinical manifestations being that of headaches, periorbital and hemifacial pains, and sometimes dizziness, nasal obstruction and recurrent sinusitis, among others $(2,3)$. The incorporation of tomographic tests performed in order to assess implant treatment has led to an increase in the diagnosis of these types of disorders, which occasionally have an apparent dental origin. Therefore, the aim of this study was to examine whether there is an interrelationship between the data collected during the medical history evaluation and in the clinical examination and that of the radiographic findings, by determining the morphology of such findings. Finally, we wish to establish whether a correlation exists between the images provided by the panoramic radiograph and those of the CT.

\section{Material and Methods}

We have reviewed 152 patients who presented the absence of at least two antral teeth, and who were subjected to a panoramic radiograph and subsequent CT scan in order to establish an implant diagnosis. Of these patients, 42 were selected, in which we observed 84 maxillary sinuses that presented unilateral or bilateral sinus abnormalities in the radiographic evaluation. The following method was used for collecting data:

documention of the clinical history, in which respiratory abnormalities were noted, including allergies, nasal septum deviation, catarrhal processes or other disorders. In addition, we evaluated whether the the patients had noted any type of sinus symptoms during that year.

A clinical examination was performed, observing the treatments or dental disorders as well as the absence of antral teeth in both upper regions, and a radiographic examination by means of panoramic display in addition to a computerized tomographic study were also carried out. In both studies, we tried to detect the existence of sinus disorders, whether in the form of dome-shaped images, suggestive of mucous cysts or swellings characteristic of mucosal hyperplasia. From a descriptive point of view, the data was collected from these alterations according to their location and morphology.

\section{Results}

The average age of the patients in this study was 59.8 years old, with a higher frequency of sinus pathology noted starting in the sixth decade of life. With regard to sex, there was a slight predominance of males $54.76 \%$, compared to $45.23 \%$ females, ratio male:female $=1: 0.8$.
While finding out about the patient's medical history, we were able to discover the existence of respiratory disorders in 22 patients, accounting for $52.38 \%$ of the total sample; $63.63 \%$ reported hay fever, $22.72 \%$ reported catarrhal process, and $13.63 \%$ had bronchial asthma.

Only 7 patients reported having symptoms during the year prior to the examination, consisting of stuffy nose, headache and runny nose.

In the intraoral examination, we observed the absence of two antral teeth in 17 patients ( $40.47 \%$ ), three in 15 patients $(35.71 \%)$ and more than three in 10 patients $(23.80 \%)$.

With regard to the dental examination, periodontal disease was found in 16 patients (38.09\%) and endodontic treatment with apical disorders were found in 8 patients (19.04\%).

Of a total of 84 maxillary sinuses for the 42 patients, radiographic abnormalities were detected in 56 maxillary sinuses. The panoramic radiograph enabled this observation in 16 maxillary sinuses, corresponding to 12 patients.

Compared with the $28.57 \%$ of the diagnostic ability of the panoramic radiograph, the tomographic study enabled diagnosis with detailed information on the characteristics of the wound in $100 \%$ of the cases. Thus, in 41 sinuses $(73.21 \%$ ), the images were consistent with mucosal hyperplasia, compared with 15 sinuses $(26.78 \%)$, in which the image observed was a "domed appearance" consistent with mucous cyst. Three-dimensionally, the mucosal hyperplasia had a regular dense ray pattern in $20 \%$ of the cases, compared to irregular radiodensities in $80 \%$ of the cases (Fig. 1). With respect to its location, all of them affected the sinus floor, extending to different walls, with the following distribution: anterior and medial wall (29.26\%), anterior and lateral wall (29.26\%) anterior, lateral and medial wall (36.58\%) and anterior, lateral, medial and posterior wall (4.87\%) (Table 1).

Of the 15 sinuses with dome-shaped images (Fig. 2), 9 were located in the anterior wall $(60 \%), 3$ in the medial wall $(20 \%), 2$ in the lateral wall (13.33\%) and 1 in the posterior wall (6.66\%) (Table 2).

By correlating the images with medical history data and examinations, we found the following percentages of correlation: in the 15 cases with unilateral mucous cyst, 5 patients $(33.33 \%)$ had a history of respiratory disorders, 6 patients had previous treatments or dental pathology $(40 \%)$, and there were 4 patients with no apparent relationship (26.66\%).

In the 27 patients with observation of 54 maxillary sinuses, there were 41 disorders corresponding to hyperplasias, 17 of which $(31.48 \%)$ presented a history of respiratory disorders, compared with $28(51.85 \%)$ with endodontic treatments and periodontal disease. In 12 of the maxillary sinuses (22.22\%), we were unable to show a respiratory or dental correlation due to an absence of such disorders. 


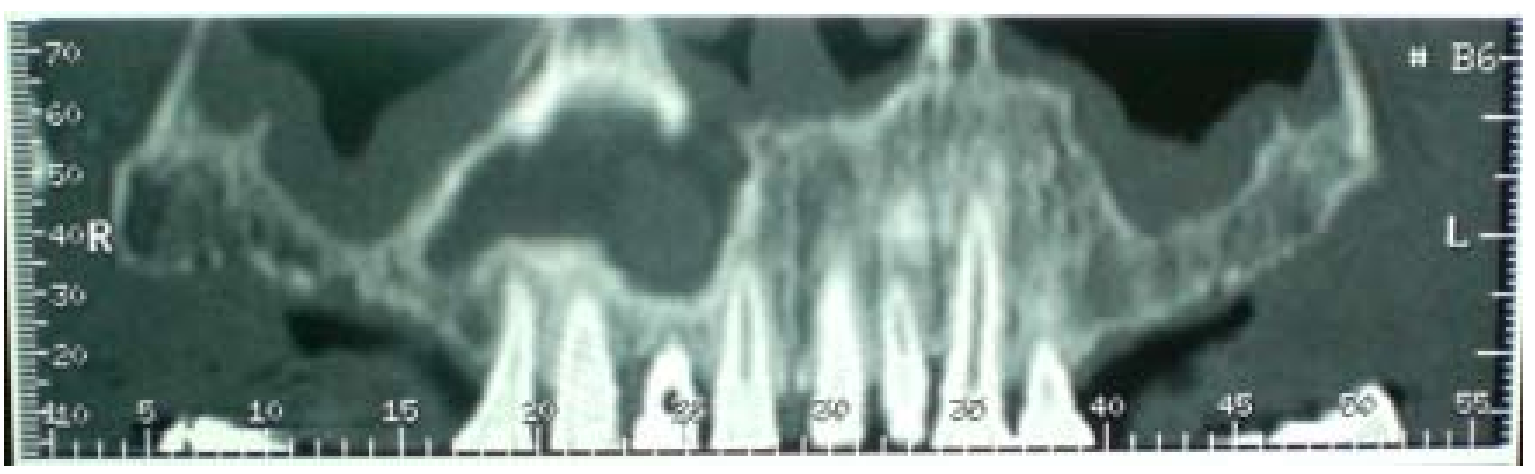

Fig. 1. CT panoramic scan in which mucosal hyperplasia can be observed.

Table 1. Distribution in percentages according to the location of the hyperplasia.

\begin{tabular}{|c|c|c|c|c|}
\hline $\begin{array}{c}\text { Hyperplasias } \\
\text { n: } 41\end{array}$ & Anterior, medial wall & Anterior, lateral wall & $\begin{array}{c}\text { Anterior, lateral, } \\
\text { medial wall }\end{array}$ & $\begin{array}{c}\text { Anterior, lateral, medial, } \\
\text { posterior wall }\end{array}$ \\
\hline$\%$ & 29.26 & 29.26 & 36.58 & 4.87 \\
\hline
\end{tabular}

Table 2. Distribution in percentages according to the location of the mucous cysts.

\begin{tabular}{|c|c|c|c|c|}
\hline $\begin{array}{c}\text { Mucous cyst } \\
\text { n: } 15\end{array}$ & Anterior wall & Medial wall & Lateral wall & Posterior wall \\
\hline$\%$ & 60 & 20 & 13.33 & 6.66 \\
\hline
\end{tabular}



Fig. 2. CT panoramic scan in which a dome-shaped image can be observed.

\section{Discussion}

This study attempted to focus on cystic lesions and hyperplastic sinus lesions by means of data collection and analysis of panoramic radiographs and CT.

With respect to age, we can confirm that our overall results are consistent with those of other authors who have observed an increased frequency of sinus pathology starting with the sixth decade of life $(4,5)$. However, in the specific case of mucous cysts, this average age is higher than that observed by Maeda et al. (6) and Ruprecht et al. (7), who found an increased frequency in patients in the third decade of life.
With respect to the patient's sex, although there were slightly more males versus females, we agree with other larger studies which concluded that there is no difference in the cystic sinus pathology associated with the patient's sex.

In our opinion, one of the most unknown aspects among stomatologists and dental professionals is the etiological factor that triggers these sinus disorders which, although there may be a clear interrelation with rhinogenous factors, dental factors are also involved.

In this study, $52.38 \%$ of the cases presented respiratory disorders, a history of hay fever being the most frequent. 
Authors such as Allard et al. (8) have considered the role of allergies as that which triggers these processes, although, like other authors (9-10), they consider that the percen-tages may vary according to seasons of the year, with winter likely to play a role due to the low temperatures, and summer due to the use of airconditioners.

The role of odontogenic factors in sinus pathology is being explored due to the intimate relationship that the maxillary sinus has the with the dental alveoli and its roots, mainly molars and premolars (11). Hence, Eberhardt (12) conducted a study with CT in which he measured the distances between the maxillary sinus floor and the tips of the posterior maxillary molars, finding that the tips of the molars were generally closer to the sinus than the premolars, especially the mesiobuccal root of the second upper molar. Other authors (13) emphasize that depending on the degree of sinus pneumatization, the roots can be projected into it, even some of the tips can become coated only by the sinus mucosa. In other studies using CT, similar results were obtained regarding the distance between the roots and the sinus, and it was found that a small percentage of patients had roots that extended into the walls of the sinus.

By virtue of this clear relationship, authors such as Soikkonen et al. (14) observe a clear frequency (70\%) of sinus mucosal thickening in dentulous patients compared with edentulous patients, therefore defending the hypothesis of a possible odontogenic origin in the thickening of the mucosa.

Along the same line, Falk et al. (15), in their evaluation of the influence of periodontal treatment on the sinus mucosa, noted that severe periodontitis sustained over time could trigger a sinus mucosal thickening and that periodontal treatment was successful in bringing it under control.

In our study, a total of 24 patients had periodontal problems or apical lesions, and of these, 19 were not related to respiratory issues. It is therefore very likely that dental alterations were the etiological factor of such apical lesions, which in turn would enable us to establish an absolute value close to that of $35 \%$.

From a radiographic point of view, the maxillary sinus can be seen very clearly on panoramic radiographs, as mucous cysts are often diagnosed accidentally in such radiographs.

In this study, the diagnostic capacity of panoramic radiography was determined to be $28.57 \%$, in most cases enabling the presumptive diagnosis of mucious cysts. This percentage, although considerable, is limited to the diagnosis of mucosal hyperplasia, as they are smaller than mucous cysts and due to the overlapping of anatomical structures. Hence, authors such as McDonald et al. (16), Ohba (17), Mattila (18) and Wilson et al. (19), have felt, like us, that the panoramic radiograph, which is still the first test to be requested in the dental practice, is not a good method for diagnosising sinus disorders. Given these limitations, CT represents the most effective diagnostic testing available, due to its panoramic, axial and transverse scans, offering a spacial view of these alterations as well as their morphology, and hence the suspicious diagnosis is more accurate.

Mucous cysts and hyperplasia were clearly observed in $100 \%$ of the cases. The former are located preferentially in the anterior wall (60\%) and medial wall (20\%). Attempting to establish a single etiological factor for this process can be risky. Of the 15 cases found, 5 patients had respiratory problems, 6 had apical responses or periodontal disease, and 4 had no apparent related pathology, although we can not exclude the dental factor given the absence of antral teeth.

\section{References}

1. Yuca K, Bayram I, Kiroğlu AF, Etlik O, Cankaya H, Sakin F, et al. Evaluation and treatment of antrochoanal polyps. J Otolaryngol. 2006;35:420-3.

2. Melén I, Lindahl L, Andréasson L, Rundcrantz H. Chronic maxillary sinusitis. Definition, diagnosis and relation to dental infections and nasal polyposis. Acta Otolaryngol. 1986;101:320-7.

3. Brook I. Microbiology of acute and chronic maxillary sinusitis associated with an odontogenic origin. Laryngoscope. 2005;115:823-5. 4. Coleman H, Meer S, Altini M, Reyneke J, Becker P. Maxillary sinus pathology in 119 patients--a histopathologic study. SADJ. 2005;60:140, 142-5.

5. Gardner DG, Gullane PJ. Mucoceles of the maxillary sinus. Oral Surg Oral Med Oral Pathol. 1986;62:538-43.

6. Maeda Y, Osaki T, Yoneda K, Hirota J. Clinico-pathologic studies on post-operative maxillary cysts. Int J Oral Maxillofac Surg. 1987;16:682-7.

7. Ruprecht A, Batniji S, el-Neweihi E. Mucous retention cyst of the maxillary sinus. Oral Surg Oral Med Oral Pathol. 1986;62:728-31.

8. Allard RH, van der Kwast WA, van der Waal I. Mucosal antral cysts. Review of the literature and report of a radiographic survey. Oral Surg Oral Med Oral Pathol. 1981;51:2-9.

9. Lopatin AS, Sysolyatin SP, Sysolyatin PG, Melnikov MN. Chronic maxillary sinusitis of dental origin: is external surgical approach mandatory? Laryngoscope. 2002;112:1056-9.

10. Yamamoto H, Takagi M. Clinicopathologic study of the postoperative maxillary cyst. Oral Surg Oral Med Oral Pathol. 1986;62:544-8.

11. García B, Martorell L, Martí E, Peñarrocha M. Periapical surgery of maxillary posterior teeth. A review of the literature. Med Oral Patol Oral Cir Bucal. 2006;11:E146-50.

12. Eberhardt JA, Torabinejad M, Christiansen EL. A computed tomographic study of the distances between the maxillary sinus floor and the apices of the maxillary posterior teeth. Oral Surg Oral Med Oral Pathol. 1992;73:345-6.

13. Oberli K, Bornstein MM, von Arx T. Periapical surgery and the maxillary sinus: radiographic parameters for clinical outcome. Oral Surg Oral Med Oral Pathol Oral Radiol Endod. 2007;103:848-53.

14. Soikkonen K, Ainamo A. Radiographic maxillary sinus findings in the elderly.Oral Surg Oral Med Oral Pathol Oral Radiol Endod. 1995;80:487-91.

15. Falk H, Ericson S, Hugoson A. The effects of periodontal treatment on mucous membrane thickening in the maxillary sinus. J Clin Periodontol. 1986;13:217-22.

16. MacDonald A, Newton CW. Pseudocyst of the maxillary sinus. J Endod. 1993;19:618-21.

17. Ohba T. Value and limitation of panoramic radiography in the diagnosis of maxillary sinus pathosis. Int J Oral Surg. 1977;6:211-4. 18. Mattila K. Roentgenological investigations into the relation bet- 
ween periapical lesions and conditions of the mucous membrane of maxillary sinuses. Acta Odontol Scand. 1965;23:Suppl 42:1-91.

19. Wilson PS, Grocutt M. Mucosal thickening on sinus X-rays and its significance. J Laryngol Otol. 1990;104:694-5. 